\title{
A Experiência do Letramento Digital para Professores Municipais do Ensino Básico Durante a Pandemia COVID-19
}

\author{
Maria Erilane L. da Silva ${ }^{1}$, Anny Alice L. Gama ${ }^{1}$, Francisco Victor da S. Pinheiro ${ }^{1,2}$, \\ Carla I. M. Bezerra ${ }^{1,2}$, Wladimir A. Tavares ${ }^{1}$, Paulo de Tarso G. Oliveira ${ }^{1}$ \\ ${ }^{1}$ Universidade Federal do Ceará (UFC) - Quixadá - CE - Brasil \\ ${ }^{2}$ Programa de Pós-Graduação em Computação (PCOMP) \\ \{mariaerilane12, annyalice, victor.pinheiro.ce\}ealu.ufc.br \\ \{carlailane, wladimir, paulodetarso\}@ufc.br
}

\begin{abstract}
This work aims to present an experience report on the digital literacy given to teachers from the municipal teaching network of Quixadá, as an extension action at the Federal University of Ceara - Campus Quixadá. The course was taught virtually to 217 teachers of basic education. The report presents the methodology and evaluation carried out with the teachers. As a evaluation result, it was found that the course was of great relevance, since $77.8 \%$ of the teachers managed to apply the content in the classroom and $19.4 \%$ still intend to apply it.
\end{abstract}

Resumo. Este trabalho tem como objetivo apresentar um relato de experiência sobre o letramento digital ministrado para professores da rede municipal de ensino de Quixadá, como ação de extensão da Universidade Federal do Ceará - Campus Quixadá. O curso foi ministrado virtualmente para 217 professores da educação básica. O relatório apresenta a metodologia e avaliação realizada com os professores. Como resultado da avaliação, constatou-se que o curso foi de grande relevância, visto que 77,8\% dos professores conseguiram aplicar o conteúdo em sala de aula e 19,4\% ainda pretendem aplicá-lo.

Palavras-chave. Letramento Digital; Ensino Remoto; Tecnologia da Informação.

\section{Introdução}

Para conter o avanço da pandemia COVID-19 no Brasil e no mundo, todas as instituições de ensino tiveram que adotar a modalidade de ensino remoto. O ensino remoto já vem sendo utilizado a bastante tempo pelas universidades, geralmente como um complemento ao ensino presencial [Clark and Mayer 2016]. No entanto, devido a pandemia, a transição entre essas modalidades de ensino tiveram que ser realizada de maneira urgente, exigindo considerável esforço dos alunos e educadores para se adaptarem a essa nova realidade. A literatura destaca certas deficiências dessa transição, como a fraqueza da infraestrutura de ensino online, a inexperiência dos professores, a lacuna de informações, o ambiente complexo em casa e outros fatores [Daniel 2020].

Sabe-se, que o aprendizado online tem inúmeros desafios, como: método de transmissão do conteúdo (síncrono e assíncrono), criação e adaptação de conteúdo, facilitação da aprendizagem colaborativa, avaliação e infraestrutura [Moubayed et al. 2018]. 
Além desses desafios, o professor precisa definir estratégias para o suporte ao aluno e a estratégia para recebimento das atividades (prazos flexíveis ou rígidos) [de Deus et al. 2020]. Para contornar esses desafios os educadores estão fazendo uso das tecnologias digitais para mediar o processo de aprendizagem remota. $\mathrm{O}$ ensino remoto praticado na pandemia assemelha-se ao Ensino à Distância $(\mathrm{EaD})$ apenas no que se refere a uma educação mediada pela tecnologia [Junior and Monteiro 2020]. A tecnologia tem se inserido nos contextos educativos de forma acelerada, possibilitando novas formas de produzir e socializar conhecimentos e informações [Schneider et al. 2017]. Porém, o uso fluente das tecnologias digitais na $\mathrm{EaD}$ se constitui um desafio atual.

O Conselho Nacional de Educação (CNE) do Brasil divulgou diretrizes durante a pandemia para orientar escolas da educação básica e instituições de ensino superior ${ }^{1}$. Dentre as diretrizes propostas está a realização de atividades não presenciais durante o período da pandemia. Governos estaduais e municipais iniciaram em 2020 a retomada das atividades de ensino utilizando meios digitais, tais como videoaulas, plataformas virtuais, redes sociais ou ainda material didático impresso e entregue aos pais ou responsáveis [Araujo et al. 2020]. No entanto, muitos professores da rede municipal e estadual de diversos estados não foram capacitados para executar suas atividades remotamente.

Dessa forma, este artigo apresenta o relato de experiência do Letramento Digital ministrado para professores da rede municipal de Quixadá pelos bolsistas do Programa de Educação Tutorial (PET) e Programa de Aprendizagem Cooperativa em Células Estudantis (PACCE). A solicitação foi realizada pela própria Secretaria de Educação da cidade de Quixadá e formalizado como um projeto de extensão junto à Universidade Federal do Ceará - Campus Quixadá. O curso possibilitou aos docentes se adaptarem aos desafios do ensino remoto e conduzirem suas disciplinas da melhor forma possível, orientados por ferramentas tecnológicas que auxiliam no ensino, monitoramento e avaliação dos conteúdos ministrados.

\section{Fundamentação Teórica}

\subsection{Ensino Remoto}

Ensino remoto emergencial é o termo que vem sendo utilizado para designar o processo acelerado de transposição de metodologias e práticas pedagógicas típicas dos territórios físicos de aprendizagem para meios virtuais [Moreira et al. 2020]. Em 2020, esse processo surge em resposta às necessidade de retomadas de atividades de ensino suspensas pela medidas de contenção da pandemia COVID-19.

Diversos autores ressaltam a diferença entre o ensino remoto emergencial e Educação a Distância (EaD) [Moreira et al. 2020, Joye et al. 2020, Hodges et al. 2020, Nobre and de Oliveira Rodrigues 2020]. Na EaD, o planejamento e execução de um curso tem um modelo subjacente de educação que embasa as escolhas pedagógicas e organiza os processos de ensino e de aprendizagem [Menezes and Francisco 2020]. No ensino remoto emergencial, as escolhas pedagógicas, que no geral foram embasadas em cenários físicos de interação, são adaptadas para o modelo onde o contato espacial entre professor e aluno está restrito.

\footnotetext{
${ }^{1}$ Diretrizes CNE
} 
Na prática há uma inversão na lógica de tomada de decisões: enquanto na $\mathrm{EaD}$ as ferramentas de TICs fazem parte da escolha de um modelo pedagógico, no ensino remoto emergencial é o processo didático que se adaptada às tecnologias e habilidades de professores e alunos. Segundo [Joye et al. 2020], esse tipo de ensino remoto praticado na pandemia assemelha-se à EaD apenas no que se refere ao uso de uma educação espacialmente distante e mediada pela tecnologia digital. Ainda segundo os autores, esse tipo de ensino remoto praticado na pandemia manteve aspectos mais relacionados a da educação presencial, com o modelo expositivo tradicional.

O modelo de ensino remoto emergencial faz emergir problemas de cunho social, uma vez que a sua realização depende de condições de infraestrutura, como acesso a Internet e à equipamentos digitais que permitam acompanhar as atividades remotas, o que não era a realidade de diversos estudantes. Aliado a isso, constata-se, tanto no ensino público quanto privado, a falta de condições de formação adequada aos professores para adesão a esse formato de ensino [Menezes and Francisco 2020. Nobre and de Oliveira Rodrigues 2020].

\subsection{Letramento Digital}

Letramento digital é um termo que refere-se às competências necessárias para utilização de TICs em situações cotidianas. No uso cotidiano, assume-se que uma pessoa letrada detém a capacidade de ler, escrever, compreender e questionar [Costa and Ferreira 2020]. Com o uso crescente de recursos e mídias digitais, novas exigências de aprendizagem são requeridas em alinhamento às necessidades dos novos modos de comunicação e, por conseguinte, de letramentos e linguagens que o tempo presente traz [Moura 2019]. O letramento digital possibilita assim a detenção competência nestes novos meios de produção de informação e de comunicação.

Sob a ótica do Ensino, existem diversas e variadas ferramentas de TICs para apoio e desenvolvimento de uma metodologia de ensino, desde ferramentas de produtividade, como editores de texto e planilhas, à ambientes virtuais de aprendizagem [Costa and Ferreira 2020]. Um curso de letramento digital pode assim ser adotado como política de aperfeiçoamento de profissionais de educação para que técnicas de ensino e aprendizagem possam ir além da tradicional abordagem expositiva, estimulando autonomia e proatividade no aluno. Dentre os benefícios do letramento digital para professores, pode-se destacar: formação de indivíduos mais preparados para elaborar aulas e materiais; uso correto dos canais de comunicação (seguros e com informações confiáveis); produção de conteúdos; participação e engajamento em comunidades e redes; autonomia e racionalidade; e, inclusão social [Wilson et al. 2013].

\section{Trabalhos Relacionados}

Alguns estudos na literatura tem apresentado os relatos de experiência em cursos de letramento digital. [Costa and Ferreira 2020] realizaram uma revisão sistemática da literatura sobre o letramento digital na formação de professores, seus desafios e suas possibilidades. Os autores apontam que o letramento digital, além de contribuir para a inclusão digital no ambiente escolar e em todos os contextos sociais, a incorporação e uso de tecnologias digitais na escola permitem novas possibilidades para os processos educacionais.

Em [de Deus et al. 2020], os autores analisaram os principais problemas encontrados na adoção da modalidade de Ensino Remoto Emergencial nos cursos da Área 
de Computação em várias instituições no Brasil coletando os dados utilizando um questionário web. O principal problema apontado pela pesquisa foi a falta de estratégia pedagógica. Muitos professores não tiveram tempo suficiente para adaptar seus materiais de ensino. Além disso, a maioria dos professores não tinham experiências prévias com o ensino remoto. Outros professores apontaram a falta de habilidade em realizar gravações e edições de vídeos e em utilizar um grande número de ferramentas. De forma similar, em nosso relato também foram identificados os mesmos problemas de forma ampliada, como: falta de experiência na produção de material de ensino, falta de habilidade em realizar gravações e edições de vídeos, dificuldade em utilizar ferramentas de TIC e utilização tímida de Recursos Educacionais Abertos.

[Araujo et al. 2020] conduziram um estudo de caso sobre a proposta de formação de professores para o uso de tecnologias no ensino remoto de emergência. A formação consistiu em uma palestra e duas oficinas sobre planilhas e apresentações de slides. Nessa proposta de formação, a escolha dos tópicos foram escolhidas fazendo a análise de dados coletados. No presente trabalho, foi montada uma turma piloto para ajustar o modelo de aula, conteúdo utilizado e o comportamento com relação aos prazos. Vale destacar que, no nosso relato, os professores estavam dispostos a fazer uma formação mais longa devido as políticas de progressão funcional da prefeitura.

[Dias et al. 2020] realizaram um curso de extensão para formação de 82 professores da educação básica de um colégio utilizando as ferramentas do google. No presente relato de experiência nós também realizamos um curso de formação para professores do ensino básico. Um diferencial do nosso estudo é um período mais extenso de formação, cujo conhecimento adquirido foi aplicado pelos professores em suas turmas, a medida que o conteúdo era repassado.

\section{Curso de Letramento Digital}

O curso de Letramento Digital foi ministrado para professores da rede municipal do Ensino Básico da cidade de Quixadá, a partir de uma parceria da prefeitura da cidade com a Universidade Federal do Cera - Campus Quixadá. O curso foi planejado e executado por alunos dos cursos de Tecnologia da Informação, bolsistas do Programa de Educação Tutorial (PET) e do Programa de Aprendizagem Cooperativa (PACCE). O objetivo do curso foi proporcionar aos professores uma orientação sobre ferramentas tecnológicas que auxiliam durante o planejamento e execução do ensino remoto.

O curso de letramento digital veio da necessidade da Secretaria Municipal de Educação do município de Quixadá, que organizou uma equipe pedagógica para coordenar o retorno das atividades de ensino na modalidade remota. Como estratégia, foram produzidos roteiros quinzenais para cada distrito educacional de modo a orientar atividades em casa de cada ano/turma do ensino básico municipal. Um exemplo de roteiro é ilustrado na Figura 1 .

Os roteiros foram disponibilizados em um blog ${ }^{2}$ para que professores e comunidade tivessem acesso. Os professores orientaram as atividades principalmente por meio de aplicativos de mensagens instantâneas. Foi verificado contudo a necessidade de promover uma capacitação para os professores da rede municipal de modo a ampliar o uso

\footnotetext{
${ }^{2}$ https://bityli.com/PrHaD
} 


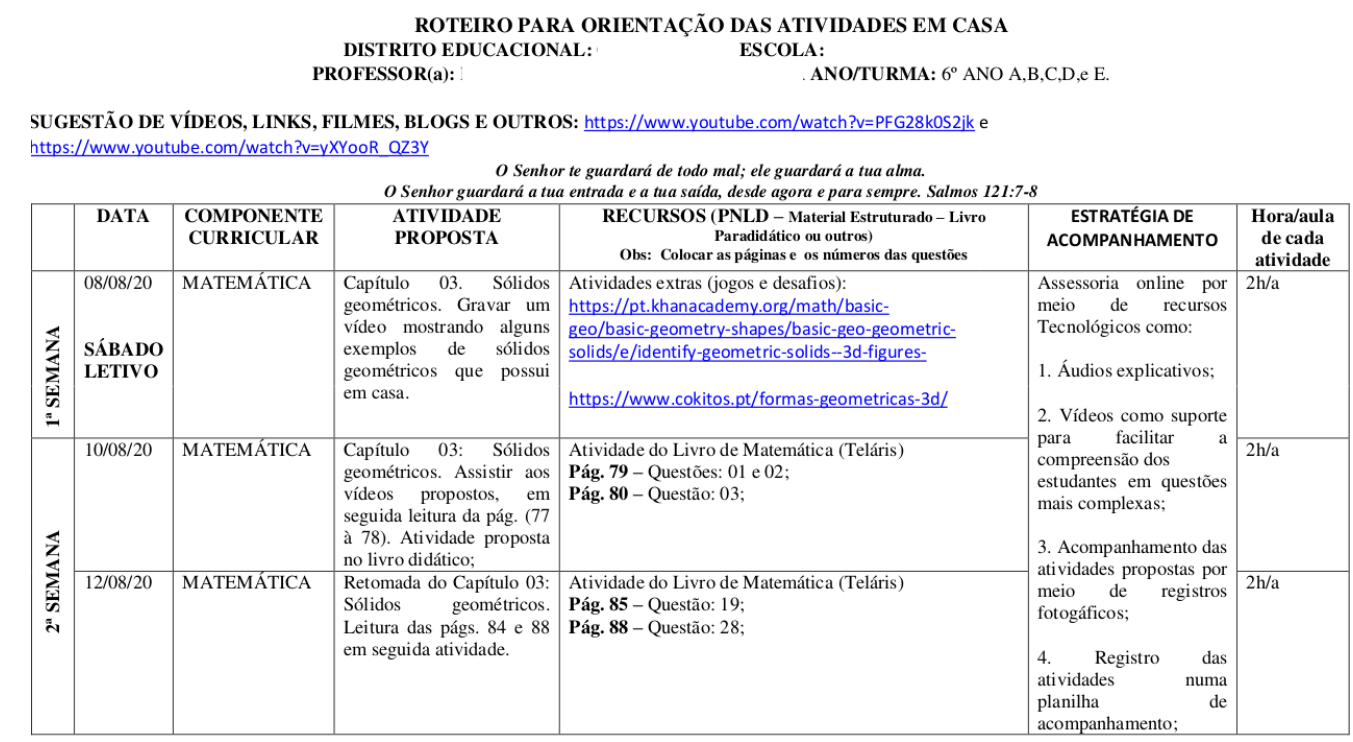

Figura 1. Exemplo de roteiro para orientação de atividades em casa.

de tecnologias da informação e comunicação na organização dos conteúdos didáticos e na interação entre estes e os alunos.

Com base na necessidade dos professores foi proposto um curso de letramento digital piloto. O primeiro curso de letramento digital foi iniciado em 17 de agosto de 2020 com duração de 3 semanas ( 3 dias de aulas no período noturno), para uma turma piloto de 20 professores. Esses professores foram escolhidos por serem mais experientes com tecnologias digitais pela própria prefeitura do município. O objetivo da turma piloto foi a experimentação da metodologia aplicada nas aulas remotas com os professores e também do conteúdo. Dessa forma, o artigo destaca o conteúdo e experiência do segundo curso de letramento digital ministrado.

O segundo curso de letramento digital foi ministrado em 19 de outubro de 2020, com duração de 5 semanas de conteúdo e uma semana extra de reflexões sobre as dificuldades em tempos de pandemia, com a participação da psicologa do campus. Os participantes foram divididos em duas turmas (Turma 1 - 98 alunos e Turma 2 - 119 alunos, totalizando 217 professores participantes). As aulas aconteceram semanalmente de forma síncrona com 2 horas de duração, nas segundas e quartas (Turma 1) e nas terças e quintas (Turma 2). Foram utilizadas as plataformas Google Meet e Google Classroom. O conteúdo do curso de 5 semanas está descrito na Tabela 1

Durante a primeira semana de aulas do curso de letramento, foram abordados os conteúdos relacionados a: (i) técnicas de pesquisas na plataforma de busca Google; (ii) noções básicas sobre as ferramentas do Google, tais como, criação e utilização do Gmail; (iii) utilização do Google Jamboard; (iv) utilização do Google Meet em relação a como criar, agendar, gravar reuniões e convidar participantes; e, (v) Youtube, com os conteúdos de como criar canal, realização de upload de vídeos e criação de playlists. Na segunda semana, foram ministrados os conteúdos exclusivos da ferramenta Google Classroom, abordando como: criar uma sala, adicionar alunos à turma, criar atividades, organizar tópicos dentro do próprio classroom e mural do classroom. As aulas foram todas de cunho prático, ministradas por meio de demonstrações e exemplos de conteúdos. 
Tabela 1. Conteúdo do curso de letramento digital.

\begin{tabular}{|l|l|}
\hline Semanas & Conteúdos \\
\hline Semana 1 & Informática básica: pesquisa no Google, criação de e-mail, ferramentas do Google, Google Meet \\
\hline Semana 2 & $\begin{array}{l}\text { Google Classroom: criar turma, adicionar alunos, adicionar atividade, material e perguntas para turma, } \\
\text { comentários e notas para atividades, devolução de atividade e rubrica. }\end{array}$ \\
\hline Semana 3 & $\begin{array}{l}\text { Google Drive: criação de pastas e arquivos, fazendo download e upload de pastas e arquivos, pesquisando } \\
\text { documentos, manipulação de arquivos bem como renomear, deletar, restaurar, mover, fazer cópias e com- } \\
\text { partilhar arquivos, documentos e pastas por meio de link de compartilhamento ou via compartilhamento } \\
\text { direto. }\end{array}$ \\
\hline Semana 4 & $\begin{array}{l}\text { Google Documentos e Google Formulários: criar, compartilhar, copiar um documento, fazer download de } \\
\text { um documento em diferentes extensões, visualizar histórico de versões, mover arquivo de pasta, inserção } \\
\text { de tabelas, imagens e comentários, formatação de texto e documento. Google Formulários: criação de } \\
\text { formulários com base em modelos prontos, adição de novas perguntas ao formulário, novo título e descrição, } \\
\text { uma imagem, vídeo ou nova seção, editando uma pergunta em múltipla escolha, resposta curta ou parágrafo, } \\
\text { excluir uma pergunta ou um item de uma pergunta múltipla escolha, reutilizar perguntas de um formulário } \\
\text { já existente e como compartilhar e adicionar colaboradores ao formulário. }\end{array}$ \\
\hline Semana 5 & $\begin{array}{l}\text { Produção de Vídeos: gravação de tela com o aplicativo XRECORDER, gravação de vídeo aulas, edição de } \\
\text { vídeo com o aplicativo VLOGIT e compartilhamento de material }\end{array}$ \\
\hline
\end{tabular}

Durante a terceira semana de aula, foram abordados os conteúdos sobre ferramentas do Google. Cada conteúdo foi elaborado de maneira a beneficiar os participantes de forma prática, fácil e objetiva. O conteúdo abordado foi sobre o Google Drive, onde se explorou os tópicos de: (i) o que é o Google drive e porque utilizá-lo; (ii) acessando e navegando o Google drive; (iii) criação de pastas e arquivos; (iv) fazendo download e upload de pastas e arquivos; (v) pesquisar documentos; e, (vi) manipulação de arquivos, bem como renomear, deletar, restaurar, mover, fazer cópias, e compartilhar arquivos, documentos e pastas por meio de link de compartilhamento ou via compartilhamento direto.

Na quarta semana do curso, o conteúdo abordado foi em relação ao Google Documentos, onde foram abordados os seguintes assuntos: (i) criar, compartilhar, fazer cópias, fazer downloads de documentos; (ii) visualizar histórico de versões, mover arquivo de pasta, inserção de tabelas, imagens e comentários; e, (iii) formatação do texto e do documento em geral. Em relação aos conteúdos sobre o Google Formulários foram abordados os seguintes conteúdos: (i) introdução ao Google formulários; (ii) criação de formulários com base em modelos prontos; (ii) adição de novas perguntas, novo título e descrição, imagem, vídeo ou nova seção ao formulário; e, (iii) edição de perguntas de múltipla escolha, resposta curta ou parágrafo.

Na quinta semana, foram tratados os conteúdos sobre: (i) produção de vídeos, onde foi abordado os tópicos relacionados à gravação de tela com o aplicativo XRECOR$D E R$; (ii) gravação de videoaulas; (iii) edição de vídeo com o aplicativo VLOGIT; e, (iv) compartilhamento de material. As aulas foram ministradas de forma prática, realizando a execução dos conteúdos nas ferramentas citadas. Na sexta semana, foi realizada uma semana extra com a participação da psicóloga do Campus UFC Quixadá, onde foram abordados os tema: (i) saúde mental em tempos de pandemia; (ii) relação do trabalho e família; e, (iii) dificuldades com o ensino remoto.

Todas as aulas que ocorreram ao longo do curso foram gravadas e disponibilizadas no Google Drive e Youtub $\epsilon^{3}$ para que todos os participantes pudessem revê-las, servindo assim como um apoio a resolução das atividades propostas bem como para a fixação do conteúdo. Os vídeos completavam os encontros remotos para apoiar as atividades e foram

\footnotetext{
${ }^{3}$ https://bityli.com/or8fT
} 
produzidos para serem curtos e de fácil acompanhamento. Também foi criado um canal de comunicação direta entre tutores e participantes, no aplicativo de mensagens Whatsapp que serviu também como um grupo de monitoria.

Ao final do curso, os participantes que frequentaram todas as semanas e responderam as atividades propostas, receberam um certificado com uma carga horária de 120 horas. Ao todo, dos 217 inscritos no curso, 150 participantes foram certificados, 26 não foram certificados e 41 desistiram do curso.

Ao término do curso de letramento, foi realizada uma pesquisa de satisfação com os participantes por meio de um formulário eletrônico disponibilizado no grupo de Whatsapp de cada turma ${ }^{4}$. $\mathrm{O}$ fomulário avaliou a experiência dos participantes em relação à metodologia aplicada, o desempenho e o conhecimento antes, durante e depois do curso de letramento, bem como as dificuldades encontradas no caminho.

\section{Avaliação do Curso}

A avaliação do curso de letramento digital aplicada com os professores da rede municipal, foi dividida em três seções. A primeira Seção é referente aos dados demográficos dos participantes, como idade, sexo e área de atuação. A avaliação obteve 70 respondentes com idades entre 26 a 64 anos. A maior parte dos respondentes eram mulheres (84\%). As disciplinas ministradas pelos professores participantes do curso são variadas, sendo as mais frequentes: português, matemática e ensino polivalente.

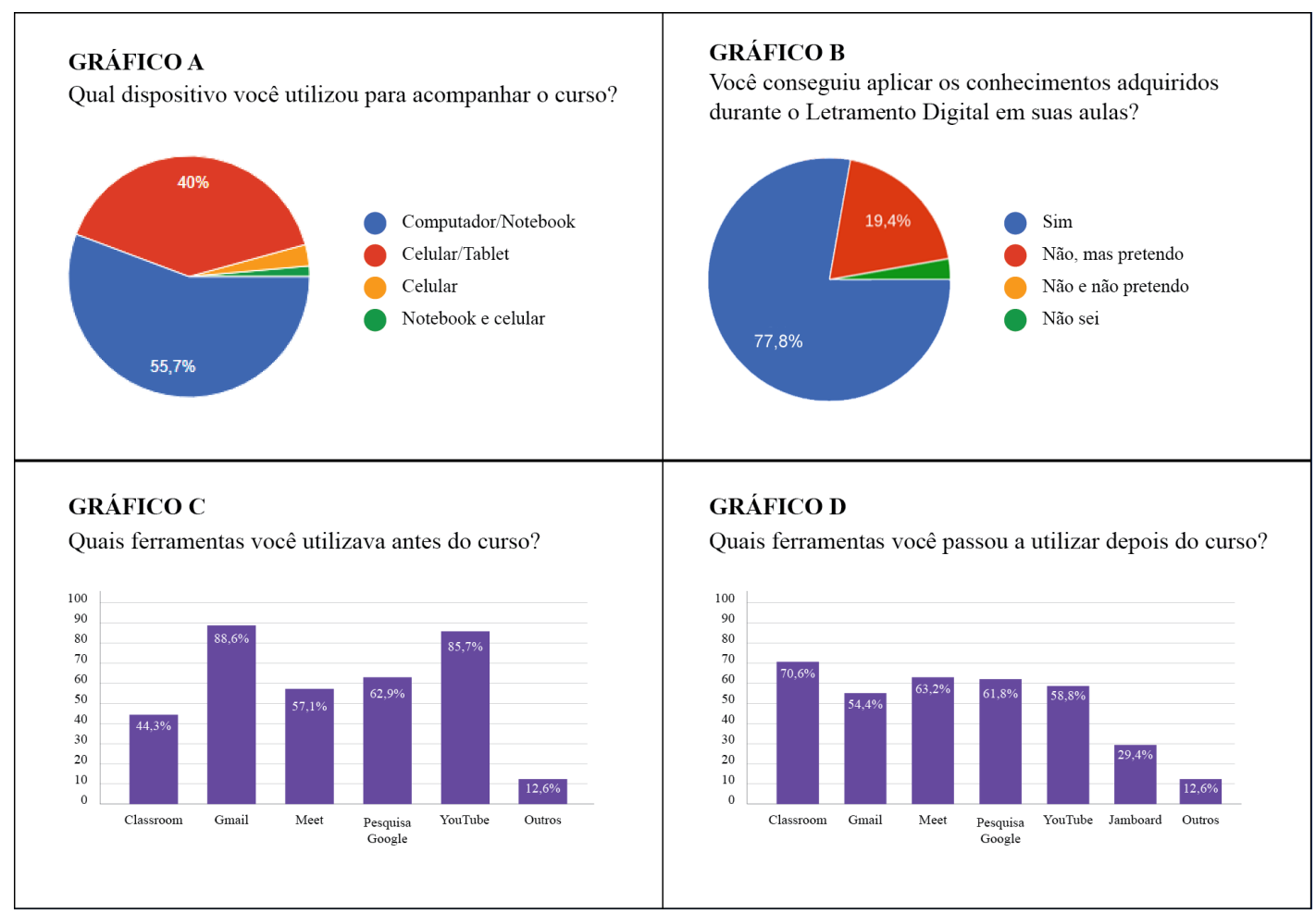

Figura 2. Dados sobre o curso de letramento digital.

\footnotetext{
${ }^{4}$ https://bityli.com/Zg6ai
} 


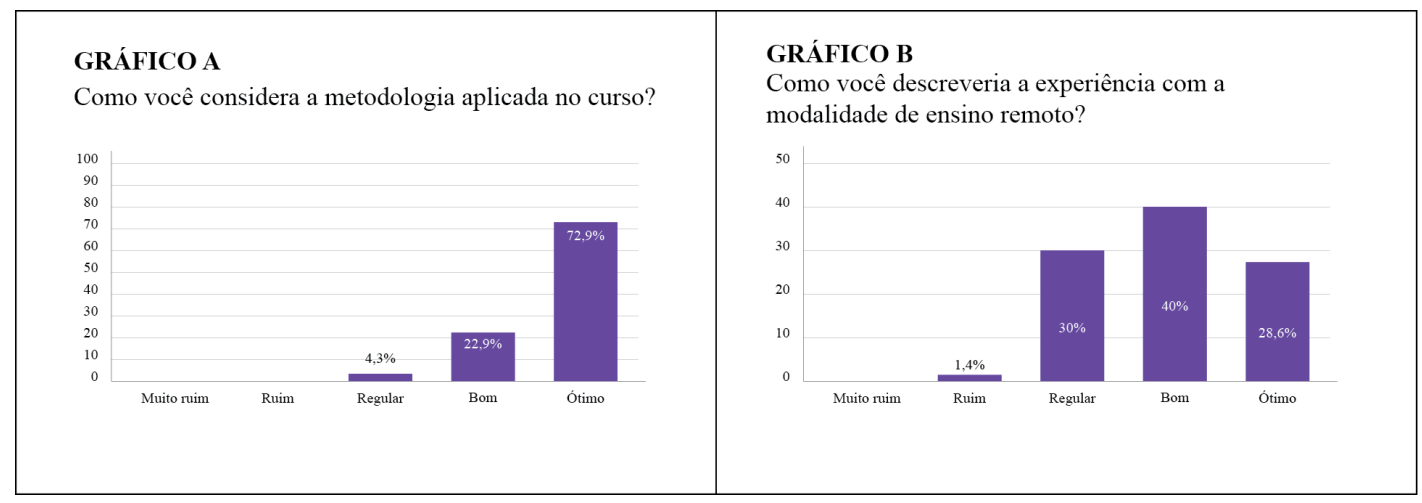

Figura 3. Dados sobre a metodologia do curso de letramento digital.

A segunda Seção, foi destinada a perguntas relacionadas com a experiência dos participantes no curso em si, cujo os resultados são apresentado na Figura 2. Foram coletados dados sobre o meio de acesso, sobre o uso das ferramentas e a aplicação dos conhecimentos adquiridos no curso durante os encontros remotos. Conforme a Figura 2 (A), a maioria dos participantes utilizaram computador ou notebook para acompanhar o curso. No entanto, muitos professores acessaram as aulas por meio do celular ou tablet. Na Figura 2(B) pode-se destacar que cerca de 77,8\% dos alunos conseguiram aplicar os conhecimentos adquiridos no curso nas disciplinas que ministram e 19,4\% dos respondentes ainda não aplicaram até o momento da avaliação, mas pretendiam aplicar. Em relação as ferramentas apresentadas, foi perguntado sobre quais ferramentas os professores utilizavam antes e passaram a utilizar depois do curso. Analisando a Figura 2, Gráficos (C) e (D), pode-se observar um salto significativo no uso de algumas ferramentas, como o Google Classroom e o Google Jamboard.

Na terceira e última Seção, foi perguntado sobre a metodologia aplicada no curso. As perguntas eram voltadas para a satisfação dos participantes do curso. A maioria aprovou a metodologia aplicada nas aulas, conforme pode-se observar na Figura 3 (A), e consideraram os materiais disponibilizados suficientes para o aprendizado. Sobre o ensino remoto, alguns professores descreveram sua experiência como neutra, mas a maioria ainda considera bom (40\%) ou ótimo (28,6\%), como é demonstrado na Figura 3 (B). Segundo alguns participantes, a modalidade remota não substitui o ensino presencial, e que estão tentando se adaptar a nova realidade.

Nesta terceira seção do formulário, foi perguntado acerca da opinião dos alunos em relação aos pontos fortes, pontos fracos, dificuldades encontradas e sugestões de melhoria para o curso. Em relação aos pontos fortes do curso, os alunos relataram que o curso foi bastante proveitoso, objetivo, rápido e com uma excelente qualidade. Corroborando com as respostas dos participantes P50 e P63 respectivamente "Um curso riquíssimo com uma ótima metodologia utilizada e um bom material de apoio, muito bem planejado e executado", "Muito proveitoso, com conteúdos atuais e essenciais para nosso dia a dia. As aulas foram bastante dinâmicas e importantíssimas, extrapolou a teoria e nos remeteu a colocarmos a mão na massa”.

Em relação a pontos fracos, os alunos relataram que o curso possuía muito conteúdo para pouco tempo, como pode-se observar no discurso do P4 "Algumas aulas foram bem rápidas e eu não assimilei nenhuma única vez, precisei rever várias ve- 
zes". Algumas dificuldades foram apontadas pelos participantes, tais como: (i) o próprio período em que o curso ocorreu (durante a pandemia, em paralelo com o semestre letivo); (ii) a dificuldade de conexão com a internet por parte de alguns bolsistas e participantes do curso; (iii) a falta de recursos tecnológicos (e.g., notebook, smartphone) por parte de alguns participantes; e, (iv) o grau de dificuldade que os mesmos apontaram do conteúdo ao início do curso (muitos não tinham familiaridade com as ferramentas apresentadas).

Algumas sugestões de melhoria para o curso de letramento, foram apontadas pelos alunos, tais como: mais conteúdos relacionados a edição de vídeo e a realização de um nivelamento dos alunos no período das inscrições, como se observa no discurso do aluno P3 "Próxima edição poderia ser apresentadas e exploradas mais opções de aplicativos de edição de vídeos, nosso principal aliado nas aulas remotas. Na inscrição do curso deveria ter perguntas direcionadas, quanto aos conhecimentos dos cursistas perante aos conteúdos, ou melhor, ferramentas, que farão parte do currículo do curso, seria melhor para os tutores saber o nível de conhecimento do público, no qual está trabalhando e assim usar linguagem apropriada facilitando a compreensão do cursista". Na perspectiva dos ministrantes do curso também foram identificadas algumas dificuldades, como: (i) o período e a modalidade do curso (remoto) afetou a comunicação dos participantes; (ii) alguns participantes eram mais experientes que os outros o que dificultou a exposição e o nível de detalhamento do conteúdo; e, (iii) o grande número de participantes nas turmas.

Apesar das dificuldades relatadas, o letramento digital relatado formou um grande número de professores da rede municipal de Quixadá para ministrar as disciplinas por meio do ensino remoto. A partir desse aprendizado foi possível minimizar o impacto do repasse do conteúdo nas disciplinas, devido as novas tecnologias e ferramentas utilizadas.

\section{Conclusão}

Este artigo apresentou a experiência da Universidade Federal do Ceará - Campus Quixadá na execução do curso de Letramento Digital para professores da rede municipal. De acordo com os resultados obtidos da pesquisa aplicada ao fim do Letramento, 72,9\% dos cursistas consideraram que a metodologia aplicada foi ótima, tal como a experiência de estudo através da modalidade de ensino remoto nos retornou que $40 \%$ dos participantes a descreveriam como boa e $28,6 \%$ como ótima. O resultado mais animador foi que $77,8 \%$ dos professores disseram que aplicaram os conhecimentos adquiridos e 19,4\% ainda pretendem aplicar. O que reforça a importância do Letramento Digital, principalmente nas condições de reclusão social devido a uma pandemia. Esse dado também abre margem para a expansão da atividade e capacitação de cada vez mais professores da rede de ensino municipal. Como trabalhos futuros pretende-se: (i) estender o curso de letramento digital para professores de outros municípios do Ceará; e, (ii) avaliar o impacto do curso do letramento digital no ensino remoto.

\section{Referências}

Araujo, J. A. S., Brito, S. S., de Amorim, V. J. P., Almeida, S. M. F., and de Assis, G. A. (2020). Formação de profissionais da educação básica na pandemia: Um estudo de caso. In Anais do XXXI Simpósio Brasileiro de Informática na Educação, pages 92-101. SBC.

Clark, R. C. and Mayer, R. E. (2016). E-learning and the science of instruction: Proven guidelines for consumers and designers of multimedia learning. John Wiley \& Sons. 
Costa, C. and Ferreira, R. (2020). Revisão sistemática sobre letramento digital na formação de professores: desafios e possibilidades. In Anais do XXXI Simpósio Brasileiro de Informática na Educação, pages 282-291, Porto Alegre, RS, Brasil. SBC.

Daniel, J. (2020). Education and the covid-19 pandemic. Prospects, 49(1):91-96.

de Deus, W. S., Fioravanti, M. L., de Oliveira, C. D., and Barbosa, E. F. (2020). Emergency remote computer science education in brazil during the covid-19 pandemic: Impacts and strategies. Revista Brasileira de Informática na Educação, 28:1032-1059.

Dias, C. R. S. D., de Vilhena, V. V., Rodrigues, P. V. R., da Silva, B. C., da Silva, T. d. N. T., et al. (2020). Formação de professores da educação básica para uso das ferramentas google na educação: uma experiência extensionista em tempos de pandemia. In Anais do XXVI Workshop de Informática na Escola, pages 349-358. SBC.

Hodges, C., Moore, S., Lockee, B., Trust, T., Bond, A., et al. (2020). The difference between emergency remote teaching and online learning. Educause review, 27:1-12.

Joye, C., Moreira, M., and Rocha, S. (2020). Educação a distância ou atividade educacional remota emergencial: em busca do elo perdido da educação escolar em tempos de covid-19. Research, Society and Development, 9:521974299.

Junior, V. and Monteiro, J. (2020). Educação e covid-19: As tecnologias digitais mediando a aprendizagem em tempos de pandemia. Revista Encantar-Educação, Cultura e Sociedade, 2:01-15.

Menezes, S. and Francisco, D. (2020). Educação em tempos de pandemia: aspectos afetivos e sociais no processo de ensino e aprendizagem. Revista Brasileira de Informática na Educação, 28(0):985-1012.

Moreira, J. A., Henriques, S., and Barros, D. M. V. (2020). Transitando de um ensino remoto emergencial para uma educação digital em rede, em tempos de pandemia. $D i$ alogia, pages 351-364.

Moubayed, A., Injadat, M., Nassif, A. B., Lutfiyya, H., and Shami, A. (2018). E-learning: Challenges and research opportunities using machine learning \& data analytics. IEEE Access, 6:39117-39138.

Moura, K. M. d. P. (2019). Revisão sistemática sobre letramento digital na formação de professores. Texto Livre: Linguagem e Tecnologia, 12(3):128-143.

Nobre, A. P. M. C. and de Oliveira Rodrigues, C. M. (2020). Experiências da formação do docente do ensino superior no google classroom em tempos da pandemia da covid-19. In Anais do XXVI Workshop de Informática na Escola, pages 339-348. SBC.

Schneider, D., Franco, S. R. K., and dos Santos Sabrito, C. E. (2017). Atividades de ensino no moodle: Implicações da fluência tecnológica digital do professor. RENOTE - Revista Novas Tecnologias na Educação, 15(1).

Wilson, C., Grizzle, A., Tuazon, R., Akyempong, K., and Cheung, C.-K. (2013). Alfabetização midiática e informacional: currículo para formação de professores. Brasília, DF: Unesco: UFTM. 